
$\triangle$

\title{
Cotidiano e imersão no teatro de Roger Bernat: a linguagem cênica reinventada
}

Roger Bernat (encenador catalão)
Julia Guímarães (doutoranda ECA USP)

"Faço coisas com pessoas". ${ }^{1}$ Foi assim que o catalão Roger Bernat definiu, certa vez, o eixo da sua lógica como diretor teatral. Conhecido por realizar espetáculos que privilegiam a participação de não profissionais - sejam eles o público ou convidados - Bernat é atualmente um dos artistas mais referenciais da cena contemporânea espanhola. Com trajetória que acumula duas décadas, o diretor se destaca pela contundência política e estética de suas investigações, ao operar, através de seus trabalhos, constantes metamorfoses sobre o que se entende por teatro.

Desde 2008, Bernat dialoga com uma vertente cênica na qual a ideia de obra coincide com a criação de inventivos dispositivos de participação do público. Por meio deles, o espectador é convidado a uma experiência imersiva, na qual realiza uma série de ações: dançar (Sagração da Primavera), responder perguntas (Pendente de Voto, Domínio Público) ou reproduzir conversas (Numax-Fagor-Plus, Comedia sin Título). É também nesse período que funda sua atual companhia, a FFF (The Friendly Face of Fascism).

Antes disso, porém, os trabalhos documentais e ensaísticos de Bernat realizados no início dos anos 2000 já lhe conferiam ampla visibilidade. Por exemplo, com o ciclo Buena Gente (2002-03), no qual o diretor dividia a cena com convidados vindos de diversas áreas - como um mago, um hacker de internet e uma transexual. Ou no espetáculo Amnésia de Fuga (2004), em que indianos e paquistaneses residentes em Barcelona reproduziam no palco seus ambientes de trabalho - os

\footnotetext{
${ }^{1}$ Disponível em: http://rogerbernat.info/teatre/2004_AMNESIA_DE_FUGA/Texts/dosier.pdf. Acesso em 25 nov. 2015.
} 
locutórios - para falar do cotidiano no contexto comum de imigração.

Com estudos inacabados em arquitetura e pintura, o diretor costuma dizer que chegou tarde ao campo das artes cênicas. "Até os 24 anos, nunca tinha ido ao

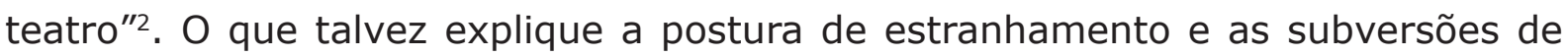
linguagem que caracterizam sua trajetória. Sua formação em direção e dramaturgia acontece no Institut de Teatre (Barcelona), em 1996. No mesmo ano, funda a companhia General Elèctrica, que segue até 2001 e se destaca por trabalhos como 10.000 Kgs e Comfort domèstic.

Presença constante nos festivais de teatro mundo afora, os espetáculos de Bernat também têm circulado com frequência pelo Brasil. Só em 2015, foram apresentados em capitais como Rio de Janeiro (Tempo Festival), São Paulo (Oficina Cultural Oswald de Andrade), Curitiba (Festival de Curitiba) e Florianópolis (Sesc Florianópolis).

E embora muitas vezes suas criações sejam enquadradas como "performance" ou "happening", o diretor catalão costuma defender a palavra "teatro" para qualificar o que faz. Pois diz enxergar aí um espaço historicamente privilegiado para se refletir sobre as reuniões que nos circundam. "O teatro, em sua essência, só se dedica a isso, a repensar nossas relações coletivas", aponta (Fig. 1).

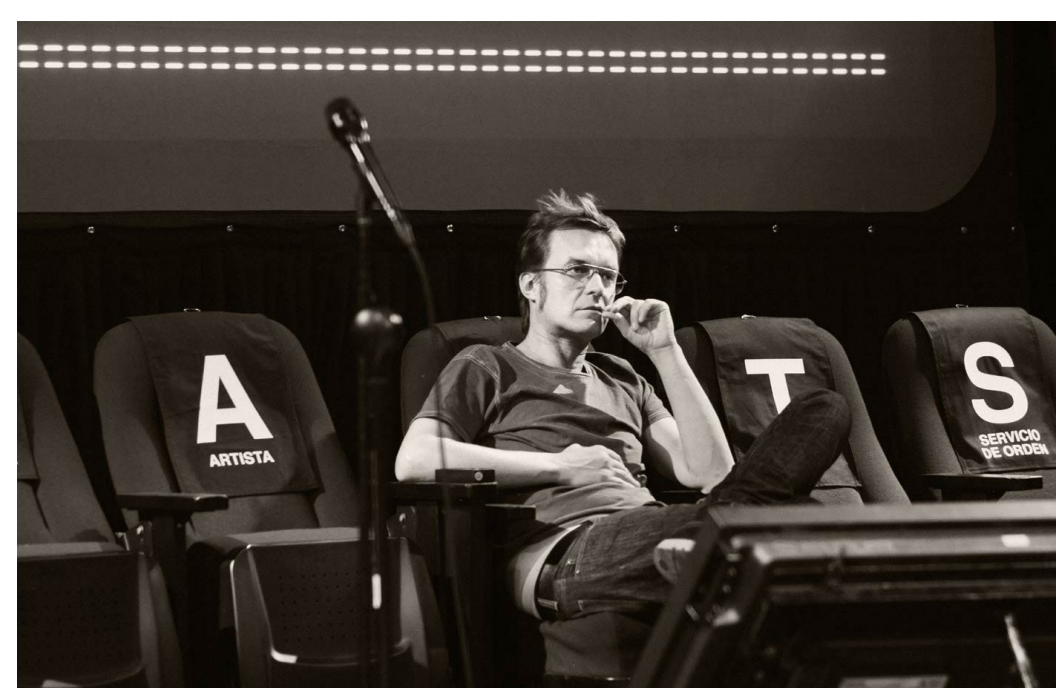

Fig. 1 - O diretor Roger Bernat no cenário de Pendente de Voto

\footnotetext{
${ }^{2}$ Em entrevista concedida à jornalista Mariana Moreira (Veja Brasília), no dia 26 de agosto de 2013. Disponível em: http://rogerbernat.info/premsa/attachment/entrevista-brasilia/. Acesso em: 25 nov. 2015.
} 


\section{Entrevista}

JG: Antes de iniciar seus espetáculos voltados para a participação do público, você tinha um trabalho com especialistas, com os não profissionais. O que te leva a trazer essas pessoas para uma criação teatral? O que te interessava neles?

RB: Acredito que começa com o tipo de interesse que sempre tive pelo teatro. Desde os meus primeiros projetos, sempre houve a presença de não profissionais, pessoas de todo tipo, taxistas, imigrantes, indianos, uma transexual, atores que não tinham uma carreira, que nunca haviam passado por estudos teatrais. Sempre houve uma certa necessidade de borrar a fronteira que existe entre a cena e o público. O princípio destes 10 anos de trabalho respondia de maneira intuitiva ao fato de que eu não sentia que a cena fosse um lugar legítimo de representação social, e como sentia essa falta de legitimidade, tinha também o impulso de trazer elementos que não fossem de teatro, de trazer o real ao teatro.

JG: E por que a cena ficcional não te parecia um lugar legítimo de representação social?

RB: Como espectador eu não conseguia fazer o pacto de ficcionalidade. Posso ir ao cinema e lograr, mas no teatro eu não conseguia conformar parte da ficção, estava mais preocupado com o real: quem eram aquelas pessoas fantasiadas, porque se moviam dessa maneira etc. Daí eu não dava o próximo passo, o de acreditar que essas pessoas eram reais. Frente a essa impotência, me vi impulsionado a trabaIhar com outros elementos.

JG: Quais nomes você utiliza para referir-se a esses participantes?

RB: Para mim sempre foram 'atores não profissionais', mas atores, pois desempenham um papel e são muito cientes da sua forma de estar em cena, que se modifica em relação à vida cotidiana, sabem que estão aí com tempo definido. E quando não aconteceu dessa forma foi muito doloroso para todos. Quando trabalhei com a garota transexual foi muito difícil, pois em cena ela relatou que se sentia como um "monstro de feira", como a mulher barbuda do século XIX, pois para ela era difícil estabelecer a diferença em relação ao papel de ativista transexual. Então havia apresentações em que ela não podia terminar, pois o olhar do outro (do público) a incomodava muito.

JG: E como era feito seu trabalho com essas pessoas que não vinham do teatro? 
RB: Quando trabalhava com atores não profissionais, havia sido através de jogos, organizamos jogos que fossem capazes de construir a cena. Com imigrantes indianos e paquistaneses, o jogo era contar viagens que fizeram ao longo de sua vida. Eu colocava algumas premissas cênicas, como contarem no proscênio, no fundo do palco, e a partir disso fixamos uma série de historias.

JG: De que maneira você chegou até as pessoas que fariam parte do espetáculo Amnésia de Fuga (2004)?

RB: Foi um trabalho de campo porque o espetáculo foi feito no Raval1. Começou a haver uma transformação no comercio tradicional da região, que pouco a pouco se converteu em comércio dirigido por indianos e paquistaneses. O trabalho de campo consistia em chegar até suas lojas e ir falar com eles, então aos poucos foi se somando um grupo de pessoas para participar do espetáculo. O mais difícil foi encontrar mulheres que aceitassem participar, justamente pelo fato de que seus papéis na vida cotidiana eram mais de backstage. Mas ao final formamos um grupo de 12 pessoas, com duas mulheres.

JG: Havia também um desejo de romper com a espetacularidade ao convidar essas pessoas?

RB: Provavelmente sim, já que em todo caso nunca me senti especialmente atraído pela ideia de espetáculo.

JG: Em um determinado momento da sua carreira, o trabalho com atores não profissionais deixa de existir e cede lugar para obras que exploram a participação do público. O que te leva a essa mudança?

RB: De repente me senti incomodado trabalhando com atores não profissionais porque o que acabava aparecendo em cena era a singularidade.

JG: Singularidade no sentido de alteridade?

RB: Havia algo de alteridade sim, mas ao final o que se gerava - e que a garota trans notou muito bem - é que o espectador exercia com seu olhar uma força e uma opressão sobre as pessoas em cena e as colocava em um lugar subalterno, já que os espectadores estavam em lugar muito cômodo quando apenas escutavam as reivindicações dessas pessoas sem perguntar em nenhum momento qual era seu papel nas situações daqueles que estavam diante deles. Então me dei conta 
de que uma coisa é denunciar as disfunções da sociedade e outra é estimular a reflexão sobre como o público provoca essas disfunções.

JG: E de que maneira essa reflexão é suscitada quando o público passa a ocupar um lugar central na cena?

RB: A partir do momento em que o público sai da obscuridade e se desloca para debaixo do foco de luz, imediatamente se converte em elemento que tem de ser observado, mirado. Por outro lado, o eixo de estar em cena cria certas dificuldades de reflexão, porque ele está inserido na ficção. Nesse sentido, ele perde um pouco da crítica, mas acredito sim que essa capacidade crítica é recuperada depois que o espetáculo termina (Fig 2).

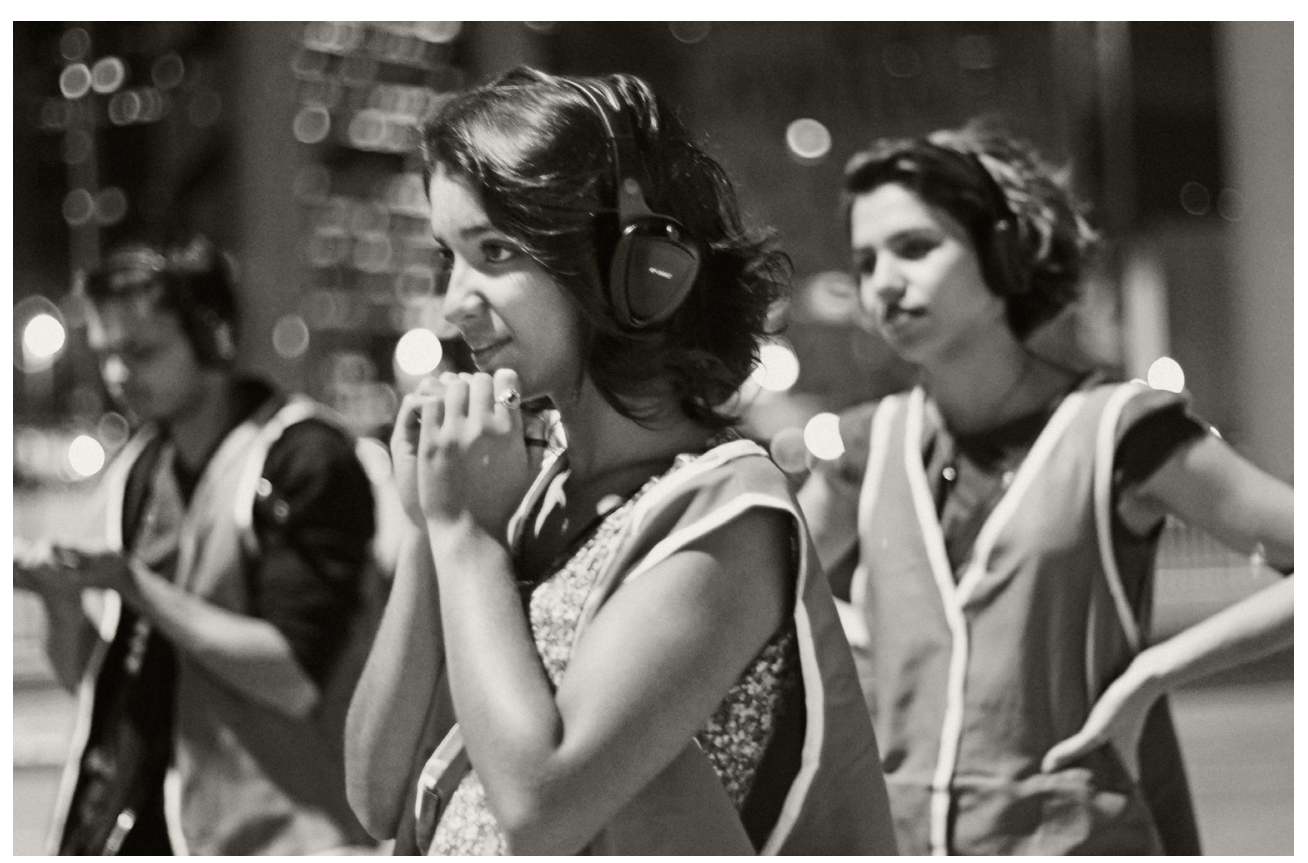

(Fig. 2 - Espectadores participam do espetáculo Domínio Público)

JG: Você quer dizer que no momento da apresentação o espectador, por estar inserido na cena, perderia sua distância crítica?

RB: Sim. A ideia de que a participação do público teria um ponto de vista crítico sobre o que se passa em cena muitas vezes é superdimensionado pelo entendimento de que quando ele está em uma sala escura sem participar teria condições de ser mais crítico com aquilo que se passa em cena. Em todo caso, há toda uma 
discussão agora em relação a essa corrente de espetáculos (nos quais o espectador participa) que reivindica um pouco uma participação privilegiada para que seja possível manter-se crítico quanto à realidade da cena. Essa é discussão que tenho bastante com o Roberto Fratini1 e evidentemente é importante que haja um olhar crítico sobre essa participação do público. No entanto, nem toda participação do público é irreflexiva assim como a participação do espectador na sala escura não necessariamente é reflexiva. Esses espetáculos que faço arrastam o público para a participação, muitos relatam que não tinham o intuito de participar no início da apresentação, mas de repente se veem dançando, por exemplo, e só depois passam a se perguntar se sua participação foi voluntária ou forçada. Qualquer dramatização coletiva tem elementos muito positivos, mas também elementos atrozes, como em qualquer festa. Todos meus espetáculos têm algo de festa. Creio que isso está totalmente ligado a essa sociabilidade efêmera que o teatro produz.

JG: Nos seus espetáculos que dialogam com a participação do espectador, percebo que em alguns o público executa ações pré-estabelecidas ou joga o papel de uma outra pessoa - como em Sagração da Primavera e Numax-Fagor-Plus - enquanto em outros ele fala por si só - caso de Pendente de Voto. Suas intenções com essas participações também são diversas?

RB: Não vejo essa diferença como você percebe, porque para mim esses trabaIhos só funcionam quando se estabelece una tensão nos espectadores entre o personagem que alguém acredita ser e aquele que decide representar durante $o$ espetáculo. Inclusive em Pendente de Voto, percebo que muitas vezes alguém se põe a criar um papel que não é o de si mesmo, até se dar conta de que não é exatamente o que acreditava ser. À medida que transcorre o espetáculo, os espectadores passam a assumir papéis que não imaginavam, como, por exemplo, o de um conservador no caso de alguém que se considerava progressista. Coisas parecidas passam em Sagração da Primavera, isso depende da construção que cada um faz de si, o espetáculo faz sacudir essa consciência prévia. Trata-se um pouco do que comentava Brecht sobre o trabalho de atores, de terem que atuar sempre o sim ou o não a respeito do personagem que vão representar, e também nos meus espetáculos é impossível que se identifique $100 \%$ com o papel que vai representar, então o espectador está se perguntando a todo tempo se o que estou convidado a fazer é o que sou (Fig. 3). 


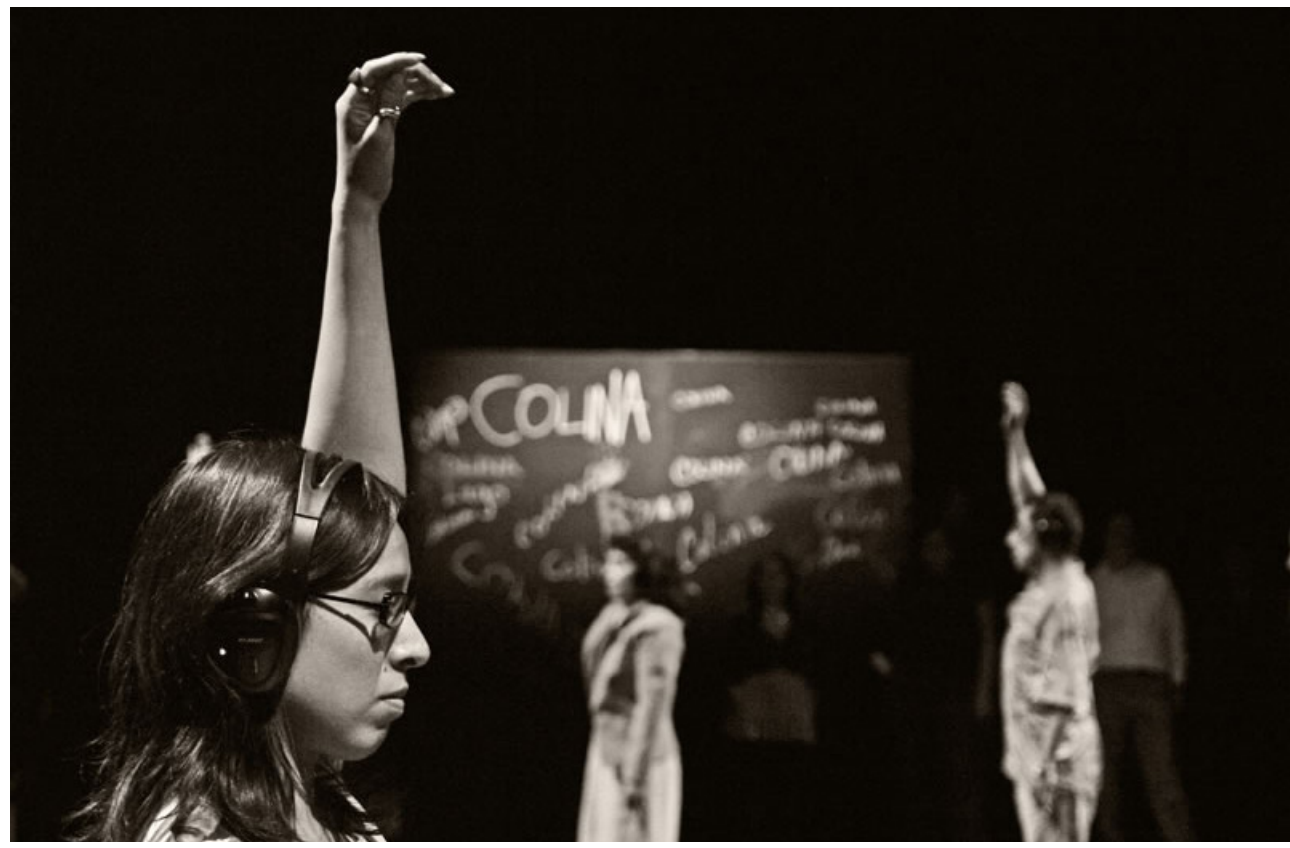

(Fig. 3 - Cena do espetáculo Sagração da Primavera)

JG: No seu trabalho com o público, me parece que a questão dos dispositivos é bastante importante para determinar o modo de participação. Como normalmente são criados os dispositivos no seu trabalho? Há, primeiro, alguma investigação temática? Ou a busca por uma linguagem, pelo dispositivo, vem antes?

RB: Acredito que normalmente começa pelo dispositivo. De perceber um dispositivo funcionando na sociedade que me pareça interessante - por exemplo, o parlamentário ou o das assembleias (caso de Pendente de Voto), ou ainda o dispositivo amoroso. No começo da criação de Numax-Fagor-Plus, o trabalho era voltado para o dispositivo amoroso. Por casualidades absurdas, a produção que faríamos com base nesse dispositivo não se desenvolveu, o que nos levou ao dispositivo das assembleias. Mas a ideia original era a de duas telas nas quais estariam presentes um homem e uma mulher lendo os textos.

JG: Nos exemplos que você dá de dispositivos que estão na sociedade, tanto o parlamento quanto as assembleias estão relacionados à ideia de democracia. Há algum interesse seu especial por essa instância?

RB: Não creio que haja algum tema que me pareça especialmente interessante. Esses exemplos são interessantes enquanto dramatizações coletivas, que podem igualmente aparecer tanto em uma assembleia como no cotidiano de um casal, 
mas também em uma festa ou uma missa. Acredito que a multitude e coletividade têm sempre a tendência a representar a si mesma. Há mais-valia simbólica no eixo de representar-se, a coletividade tem tendência a representar-se em formas que estão muito cristalizadas. Por exemplo, quando se representam em uma manifestação, todas as ordens de representação da rua estão suspendidas e aparece a manifestação unívoca e é isso que me interessa. E, por outro lado, essa mais-valia simbólica, essa representação, só o teatro a investiga, porque o teatro é justamente o lugar em que nos reunimos para pensar nas reuniões que estão ao nosso redor, já que tanto num museu quanto no cinema a relação que tenho com a obra tende a ser mais individual. O teatro, em sua essência, só se dedica a isso, a repensar nossas relações coletivas. Vamos ao teatro precisamente para isso e assim já estamos nos reivindicando como coletivo e como comunidade.

JG: Nesse sentido, o teatro estaria próximo à ideia de uma heterotopia, como um espaço que serve como espécie de incubadora para pensar outros espaços fora dele?

RB: No teatro, o que aparece é uma coletividade inócua, pacífica, onde está suspendida toda sua potencialidade cruel. É um momento, um tempo finito que damos ao teatro, ao jogo que é possível.

JG: Para o pesquisador e professor José A. Sánchez, uma característica do seu trabalho é a centralidade do diálogo com o outro e a transformação do conceito de autor. Como percebe essas duas características?

RB: Percebo que elas se multiplicaram nesse trabalho com o público. Da mesma maneira que fazia com os atores não profissionais, eu tento gerar um espaço para ocorrer coisas, para que a ficção possa se desenvolver. E nos dois casos eu não construo a ficção, e sim preparo um momento, um lugar. No trabalho atual ocorre o mesmo, mas no lugar de preparar um cenário para que os atores desenvolvam a ficção, são os espetáculos mesmos que funcionam dessa maneira.

JG: O trabalho que você apresentou na inauguração da Fundação García Lorca, em Granada, Comedia sin Título, de García Lorca, trabalha com a adaptação do dispositivo criado originalmente para Numax-Fagor-Plus. É a primeira vez que você adapta um dispositivo para aproveitá-lo em mais de um espetáculo? Como surgiu essa ideia?

RB: Sim, aqui fizemos uma adaptação de Numax e a verdade é que enquanto a 
fazia pensava que daqui a alguns anos ninguém vai acreditar que criamos o dispositivo primeiro para Numax e logo para esse novo espetáculo, Comedia sin Título1. Pois o dispositivo parece ter sido inventado por García Lorca. Na peça Comedia sin Título, há toda essa necessidade de que o público suba no palco, algo que ocorre também em outra peça dele escrita no mesmo período, El Público. Lorca queria que o público estivesse em cena. Então, a verdade é que foi uma feliz coincidência, dar-se conta de que um objeto acaba sendo útil para diferentes discursos. E isso me fez pensar que nós não fazemos tanto obras de teatro como dispositivos. Para usar um jargão filosófico, o que fazemos é criar uma técnica. E a técnica tem a particularidade de fazer reluzir algo. Então, este dispositivo é uma técnica que leva o público à cena e que o faz enfrentar sua própria identidade, seus medos, sua necessidade de estar acompanhado e toda uma série de questões que Lorca estava sublinhando em suas peças. Mas enquanto Lorca o faz de uma maneira semântica, nós fazemos de uma maneira sintática.

JG: Sintática em qual sentido exatamente?

RB: Porque ao darmos as regras do jogo, o que fazemos é criar uma regra sintática, uma linguagem. E essa linguagem tem algumas necessidades que o público mesmo vai descobrindo, e, assim, vai dar luz ao espetáculo.

JG: Nesse caso, o mesmo dispositivo serve para contextos muito distintos, pois Numax é um trabalho documental e aqui, uma ficção e uma obra dramática. Isso modifica o modo da participação?

RB: Eu diria que os dois contextos são totalmente ficcionais. Já em Numax era um contexto ficcional. Pois o filme original de Joaquim Jordà é uma ficção, pois os trabalhadores se punham a repetir o que haviam vivido meses antes. Nesse sentido, o filme era um falso documentário, no qual os operários se punham a interpretar seus próprios papéis. Então, aqui, com a peça de Lorca, temos a mesma situação, na qual os espectadores precisam interpretar seu próprio papel e dar-se conta da falsidade, da ficcionalidade e do artifício da própria realidade. E me parece que isso é o bonito dos dispositivos. Se quer a diferença que existe entre um teatro "participativo" como esse e um teatro participativo das segundas vanguardas dos anos 1960 e 1970, é que o das vanguardas tinham uma necessidade de emancipar o público, fazê-los descobrir toda sua potencialidade como seres humanos.

\section{JG: E quem sabe mudar o mundo...}


RB: $E$ evidentemente mudar o mundo e fazer a revolução. $E$, aqui, acredito que fazemos a mesma equação, porém de outro ângulo. Ou seja, o único a descobrir é que você é uma construção totalmente fictícia e, portanto, falsa. O que os trabaIhadores de Numax descobrem depois de anos de autogestão é que a identidade obreira é uma identidade imposta, que ninguém pode sentir-se obreiro, pois isso significa aceitar seu papel de subalternidade em uma hierarquia social dada. Então, nesses espetáculos, o público precisa aceitar que sua identidade como espectador é uma identidade a questionar.

JG: E isso é o que mais te interessa nesse trabalho com o público?

RB: Não apenas o que mais me interessa. Me parece que, ao questionar sua identidade como espectador, você começa a questionar suas outras identidades, sua identidade de homem, de mulher, sua identidade de pessoa iletrada ou de grandes conhecimentos literários...

JG: Nos seus trabalhos com o público, parece que há sempre uma tensão entre o dispositivo, que muitas vezes é bastante impositivo (e em Pendente de Voto há, inclusive, um metarrelato sobre isso) e a ideia de participação. A proposta é colocar esses dois elementos em tensão, criar oposições?

RB: Viver em casal significa impor-se uma série de regras. Trabalhar com mais gente ou governar um país, também. Porque, no final, precisamos adotar regras para suportar o incomensurável que é estar com desconhecidos. O que também nos coloca uma outra realidade: não há participação sem manipulação. E minha intenção com os espetáculos não é você se dar conta que é manipulado, o público já sabe perfeitamente disso. E vai ao teatro justo para ser manipulado. E quando assiste a um filme ou vai ao teatro é quando te manipulam bem (Fig. 4). 


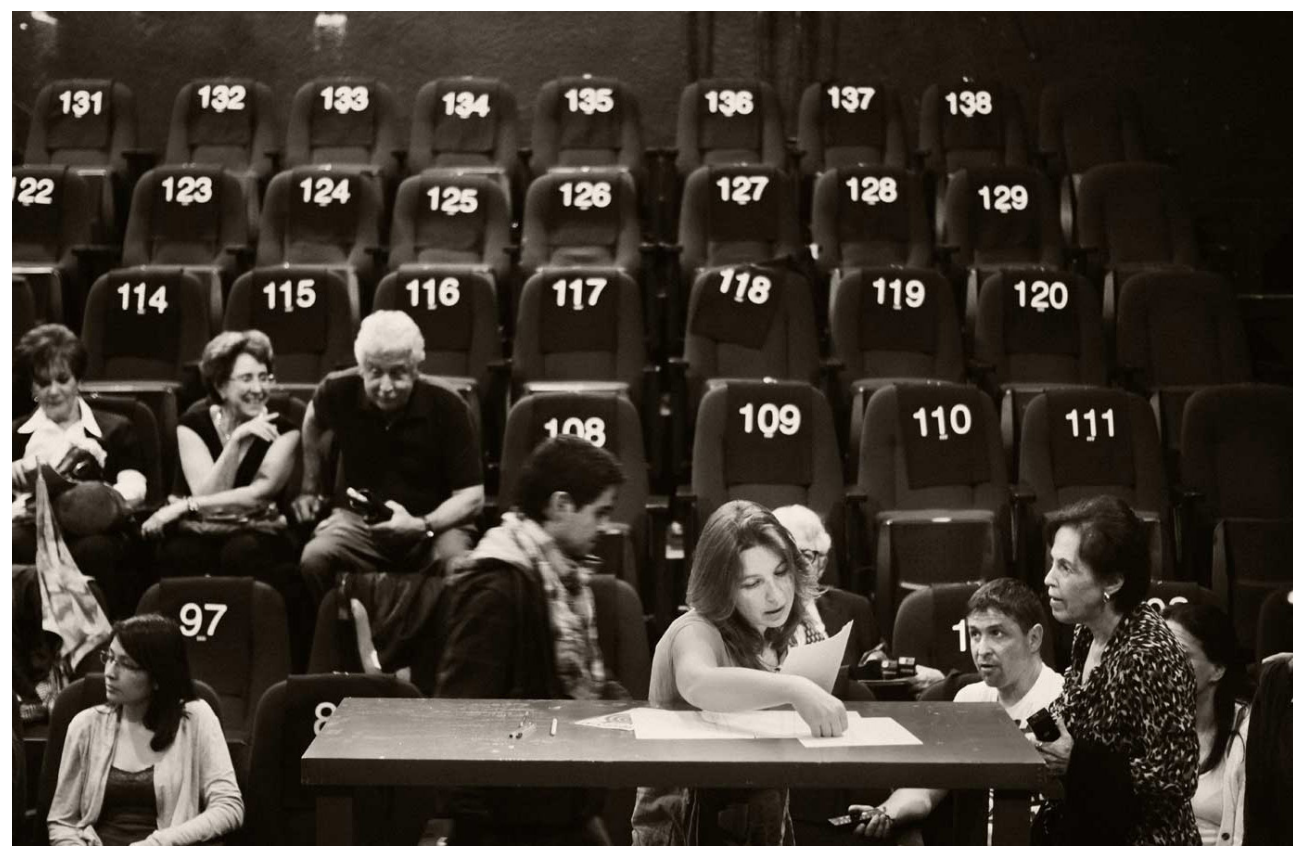

(Fig. 4 - Cena do espetáculo Pendente de Voto)

JG: Mas quando observa a reação do público nos seus trabalhos, você percebe que os espectadores sempre reconhecem a manipulação?

RB: Me parece que se alguém tem problema com a manipulação, é um problema dele. A típica resposta que sempre que tenho que dar quando há essas conversas depois da apresentação é que as pessoas me dizem: "mas eu me senti manipulado, e tal" e eu tenho que ouvir isso 20 vezes. Mas aqui pelo menos as leis da manipulação estão sobre a mesa. Antes e depois do espetáculo, a manipulação é muito maior e ninguém vai te contar. Precisamente o teatro é o lugar onde declaradamente vamos para ser manipulados a partir do nosso próprio desejo, não?

JG: E no teatro participativo, a questão das regras se torna ainda mais clara...

RB: Sim. E, afinal, o simples fato de ter que tomar a palavra, ter que mover-se, é isso o que faz te sentir-se manipulado? Mas a manipulação em que estamos metidos habitualmente é muito mais sutil. E, além disso, eu acredito que o problema da participação já está superado. Creio que estamos em outro lugar. Creio que agora estamos mais preocupados em saber quais são os lugares de socialização, ou como criar formas de socialização que passem por outros circuitos que não os circuitos impostos. E esse é um tema muito atual. Já não é mais refletir se a participação é boa ou má e, sim, ver quem propõe essa participação, onde ela nos leva. Porque, sem dúvida, teremos que participar, já que o cidadão do século XXI terá 
de responsabilizar-se pelo seu entorno, se queremos levar isso adiante. Então, que teremos de subir no palco, ocupar a cena, isso é fato. Mas como vamos fazer? Com paus, bandeiras, pelo Facebook? Como o faremos no ambiente da família? E é sobre isso que vale a pena refletir. 